\title{
Contemporary management of cancer of the oral cavity
}

\author{
Eric M. Genden - Alfio Ferlito $\cdot$ Carl E. Silver $\cdot$ Robert P. Takes • \\ Carlos Suárez • Randall P. Owen • Missak Haigentz Jr. • Sandro J. Stoeckli • \\ Ashok R. Shaha • Alexander D. Rapidis • Juan Pablo Rodrigo • \\ Alessandra Rinaldo
}

Received: 6 January 2010/Accepted: 12 January 2010/Published online: 13 February 2010

(C) The Author(s) 2010. This article is published with open access at Springerlink.com

\begin{abstract}
Oral cancer represents a common entity comprising a third of all head and neck malignant tumors. The options for curative treatment of oral cavity cancer have not changed significantly in the last three decades; however, the work up, the approach to surveillance, and the options for reconstruction have evolved significantly. Because of the profound functional and cosmetic importance of the oral cavity, management of oral cavity cancers requires a thorough understanding of disease progression, approaches to management and options for reconstruction.
\end{abstract}

This paper was written by members and invitees of the International Head and Neck Scientific Group (http://www.IHNSG.com).

\section{E. M. Genden}

Department of Otolaryngology-Head and Neck Surgery,

The Mount Sinai Medical Center, New York, NY, USA

A. Ferlito $(\varangle) \cdot$ A. Rinaldo

ENT Clinic, Department of Surgical Sciences,

Azienda Ospedaliero-Universitaria di Udine, Piazzale S. Maria

della Misericordia, 33100 Udine, Italy

e-mail: a.ferlito@uniud.it

C. E. Silver

Departments of Surgery and Otolaryngology-Head and Neck Surgery, Albert Einstein College of Medicine,

Montefiore Medical Center, Bronx, NY, USA

R. P. Takes

Department of Otolaryngology-Head and Neck Surgery,

Radboud University Nijmegen Medical Center,

Nijmegen, The Netherlands

C. Suárez · J. P. Rodrigo

Department of Otolaryngology, Hospital Universitario Central de Asturias, Instituto Universitario de Oncología del Principado de Asturias, Oviedo, Spain
The purpose of this review is to discuss the most current management options for oral cavity cancers.

Keywords Neck dissection - Oral cavity cancer . Prognosis · Treatment

\section{Introduction}

Cancer of the oral cavity comprises nearly $30 \%$ of all malignant tumors of the head and neck. Approximately $90 \%$ of cases are squamous cell carcinomas [1] while the remaining $10 \%$ represent rare malignancies (unusual forms

\section{R. P. Owen}

Division of Metabolic, Endocrine and Minimally Invasive Surgery, Department of Surgery, The Mount Sinai School of Medicine, New York, NY, USA

M. Haigentz Jr.

Division of Oncology, Department of Medicine, Albert Einstein College of Medicine, Montefiore Medical Center, Bronx, NY, USA

S. J. Stoeckli

Department of Otorhinolaryngology-Head and Neck Surgery, Kantonsspital St. Gallen, St. Gallen, Switzerland

A. R. Shaha

Head and Neck Service, Memorial Sloan-Kettering Cancer

Center, New York, NY, USA

A. D. Rapidis

Department of Head and Neck Surgery, Greek Anticancer Institute, Saint Savvas Hospital, Athens, Greece 
of squamous cell carcinoma, minor salivary gland tumors, melanomas, lymphomas, sarcomas) and a variety of malignant tumors of odontogenic origin. In North America, common risk factors for the development of cancer of the oral cavity include tobacco and alcohol use. Outside of North America, dietary habits, such as chewing betel and areca nuts present additional risks for the development of oral cancer. Beyond these risks, there is not much evidence linking dietary factors or nutritional deficiencies to the development of oral cavity cancer. The highest rates of incidence of cancer of the oral cavity occur in Pakistan, Brazil, India and France [2].

Although the use of alcohol and tobacco are independent risk factors for the development of oral cavity cancer, the synergistic effect of these two factors has been well documented [3]. It has been suggested that the use of alcohol suppresses DNA repair following exposure to nitrosamine compounds; however, the exact mechanism of the observed synergy remains poorly defined.

Human papillomavirus (HPV) is strongly associated with development of oropharyngeal cancers and a small minority of oral cavity cancers [4]. Over the past 30 years, the proportion of potentially HPV-related oral cancer in the United States has increased, an increase possibly related to changing sexual behaviors [5]. However, the exact incidence of HPV-related head and neck cancers, other than oropharyngeal cancers, remains subject to debate and may depend on epidemiological factors as well as technical improvements in the detection of HPV [6], but may also be due to misclassification of cancers of the base of tongue as oral cancers instead of oropharyngeal cancers. The association between index and second primary anogenital and oral cavity/pharyngeal cancers, strongest in never-married men, supports the influence of sexual behaviors on the risk of HPV-associated head and neck cancers [7].

Poor dental hygiene and chronic mechanical irritation have also been associated with the development of cancer of the oral cavity. When the lateral aspect of the oral tongue is exposed to mechanical friction as a result of a sharp tooth edge or irritation of the oral cavity from an illfitting denture, a cascade of events beginning with chronic irritation may lead to the development of squamous cell carcinoma. However, other, unknown factors may play a role in the association between poor dental hygiene, mechanical friction and the development of oral cancer [8].

During the last decade, a number of studies have demonstrated the significant role of genetic instability in the etiology of cancer of the oral cavity [9]. Genetic susceptibility may account for the development of oral cancer in non-smokers and drinkers and in young adults, but the precise mechanisms remain to be elucidated [10]. In addition, since 1930, the incidence of tongue cancer in young women has more than doubled and such findings strongly suggest an environmental and/or a genetic predisposition to the development of cancer of the oral cavity.

During the past 30 years, there has been an explosion of knowledge of different aspects of oral cancer. Nevertheless, despite these developments, the 5-year overall survival of this disease has advanced little, although the quality of life of patients has undoubtedly improved [11]. Although there are significant limitations to the current staging system of oral cavity cancer, it is clear that early identification, diagnosis and management of oral cavity cancer result in improved patient outcomes.

Unlike other areas of the aerodigestive tract, the oral cavity is accessible and easily examined, and as a result, screening may be considered in an effort to identify early cancers. Early detection and recognition of malignant and premalignant lesions in the oral cavity require awareness of relevant complaints and symptoms among dentists and general practitioners, as most patients will initially visit these professionals with their complaints or symptoms. Lesions, such as leukoplakia and erythroplasia need to be evaluated with appropriate biopsy, excision, or close monitoring. Primary screening may be done under the care of a primary care practitioner, dentist or head and neck/oral surgeon. Organized screening clinics could be helpful in evaluating suspicious lesions in the oral cavity.

\section{Biological behavior}

Oral cavity cancer develops through a series of molecular changes reflected as histopathological stages: through mild (low grade), moderate and severe (high grade) dysplasia to carcinoma in situ and then invasive disease [12]. The grading or classification of these premalignant or early malignant lesions is still a matter of much debate [13]. Early detection of oral lesions that will develop into invasive tumors is necessary to improve the prognosis of patients with oral cancer. However, which intraepithelial lesions will progress to invasive cancer and which will not is the subject of extensive research.

The white patches are often associated with premalignant lesions, and are commonly referred to as "leukoplakia." Leukoplakia, however, is not a pathologic diagnosis. The white patches usually represent hyperkeratosis, which may or may not be associated with atypia. Hyperkeratosis without atypia is not premalignant, while atypia without hyperkeratosis, often appearing clinically as erythroplasia, is premalignant. Waldron and Shafer [14] reviewed 3,256 tissue specimens clinically diagnosed as leukoplakia. Microscopic study showed that $80.1 \%$ were varying combinations of hyperorthokeratosis, hyperparakeratosis, and acanthosis without epithelial dysplasia. Mild to moderate dysplasia was noted in $12.2 \%$ of specimens, and severe 
epithelial dysplasia or carcinoma in situ was found $4.5 \%$. Infiltrating squamous cell carcinoma was diagnosed in only $3.1 \%$ of specimens submitted with a clinical diagnosis of leukoplakia.

\section{Prognostic indicators}

There are number of prognostic factors that determine the survival of patients and affect treatment decisions. The basic prognostic factors are tumor size (T-stage), regional nodal involvement ( $\mathrm{N}$-stage) and the presence or absence of distant metastasis (M-stage). This TNM classification is still used today with various modifications. Several other biological, molecular and histopathologic parameters have also been identified during the last decades. The prognosis of a patient suffering from oral cavity cancer is also associated with patient co-morbidity, performance status, nutritional status and immunity. Although age itself is not a prognostic indicator, co-morbidities that are commonly associated with advanced age may represent a negative prognostic predictor.

A series of histopathological features may have significant impact on the prognosis of oral cavity cancers. The presence of perineural invasion, lymphocytic response and depth of invasion are examples of histopathological parameters not accounted for in the current AJCC/UICC staging system. In addition, extracapsular spread (ECS), which may be associated with a 50\% reduction in survival, may have a significant impact on the prognosis of patients with regional disease [15].

Among other parameters particularly predictive of nodal metastasis and therefore prognosis, tumor thickness has been associated with local recurrence and survival for cancer of the oral tongue [16]. The exact depth of invasion and correlation with survival is not clear; however, several studies have suggested that tumor thickness greater than $4.0 \mathrm{~mm}$ significantly increases the risk for cervical metastases and, therefore, has a negative impact on survival [17]. Other studies have suggested that greater than $5.0 \mathrm{~mm}$ depth is associated with an increased rate of regional disease [18]. Currently, most surgical oncologists feel that tumor thickness of $4.0 \mathrm{~mm}$ or greater is associated with an increased risk for regional metastases and as a result recommend elective treatment of the clinically N0 neck even in the absence of other high-risk histopathological features. Recently, Patel et al. [19] have demonstrated that patients with thick tumors have a high risk of nodal metastases, supporting the liberal use of elective neck dissection in these patients, despite clinically negative necks. However, it is important to point out that these recommendations were established in retrospective studies, and in the context of elective neck dissection. The routine histopathologic evaluation of neck dissection specimens has been shown to be insufficient for accurate detection of micrometastases. The more sections taken from each lymph node, the more occult disease will be detected [20].

In a recent paper by Goerkem et al. [21], all known histopathologic parameters thought to predict occult lymph node metastases have been reevaluated within the context of sentinel lymph node biopsy (SLNB). In this study, neither tumor depth nor tumor thickness was predictive for occult disease. The only parameters significantly associated with the occurrence of occult disease were lymphovascular invasion, poor grading and a dissolute invasion pattern at the tumor front. The authors concluded that any squamous cell carcinoma of the oral cavity should undergo elective neck treatment, preferably by SLNB, irrespective of the measured tumor depth or tumor thickness. These results were subsequently confirmed by the studies of Bilde et al. [22] and Alkureishi et al. [23].

High-risk histopathological features that influence the risk of local regional recurrence include angioinvasion, lymphatic emboli and perineural invasion. However, the most significant prognosticator in oral cancer is the presence of ECS of lymph node metastases [24-27]. Because the presence of ECS has been identified as an indicator of poor prognosis, patients with ECS are commonly treated with adjuvant therapy, including radiotherapy and chemoradiotherapy. Yet, despite adjuvant therapy, one-third of patients will experience regional recurrence [25].

Brandwein-Gensler et al. [28] have published a riskscoring system that incorporates tumor pattern of invasion which is strongly and independently predictive of local disease free and overall survival in oral cancer. These efforts and others requiring validation will likely result in improved patient management decisions.

\section{Diagnosis and evaluation of local disease}

The initial evaluation of a patient with suspected oral cavity cancer can be relatively straightforward. A complete history, including the use of alcohol, tobacco and dietary habits as well as oral hygiene should be documented. Because the oral cavity is readily accessible, changes in the mucosa are easily identified and evaluated. Although brush biopsy has recently been used in the dental community as a screening tool, several studies suggest that the sensitivity and specificity of this technique is unacceptably low [29, 30]. A surgical biopsy represents the most reliable method of diagnosis and provides the pathologist with tissue architecture necessary to make a definitive diagnosis of invasive carcinoma.

The diagnosis of invasive carcinoma mandates a thorough evaluation to assess the extent of tumor. To delineate 
the tumor and adjacent premalignant mucosa more precisely, fluorescence may be helpful. The use of fluorescence imaging may be helpful in the detection of premalignant changes and determination of the extent of the pathologically changed mucosa [31].

Once a definitive diagnosis has been obtained, imaging is essential to determine the stage of the tumor and presence of metastasis. Although uncommon on initial presentation, the presence of distant metastasis as well as second primary cancers of the upper aerodigestive tract should be evaluated by physical examination and either chest radiography or computed tomography (CT). Although extensive lesions may be heralded by trismus, otalgia or hyperesthesia, the lack of these symptoms does not preclude invasion of the surrounding structures. CT with administration of intravenous contrast offers an initial assessment of soft tissue, bone and mucosal involvement. If there is concern regarding the invasion of the deep soft tissue, muscle or nerve, a magnetic resonance imaging (MRI) study may prove more accurate. MRI is ideal for the evaluation of soft tissue and in some cases, nerve involvement, but it may be helpful in determining bone invasion as well. Enhancement of the lingual, alveolar or trigeminal ganglion may suggest perineural involvement. The MRI scan is particularly helpful in the evaluation of non-epidermoid carcinoma (i.e. adenoid cystic carcinoma) in which perineural invasion is frequent. The overall accuracy of CT and MRI for T-staging is comparable [32]. However, CT is more affected by artifact caused by dental metals, whereas MRI is more affected by artifact caused by movements of the patient. Superficial lesions are often not demonstrated by either modality and additional imaging appears superfluous in these cases.

\section{Diagnosis and evaluation of mandibular invasion}

The mandibular cortex may be involved by adherence or direct extension of the tumor, or the medullary cavity may be involved in a more extensive manner by deeply penetrating tumor, in which case there may be far more bone involvement than is apparent on the surface. Plain radiography has been used extensively in the past, and is reasonably accurate for the diagnosis of medullary tumor invasion of the mandible; however, subtle changes associated with the cortex are more difficult to identify. The introduction of panoramic radiography, CT, MRI and bone scintigraphy with single photon emission computed tomography (SPECT) have increased the accuracy of preoperative imaging and staging.

Significant debate still exists regarding the optimal modality or combination of modalities recommended for preoperative assessment. In general, bone involvement is usually underestimated by CT, whereas with MRI and bone scintigraphy with SPECT the involvement is often overestimated [33, 34]. A negative MRI or bone scan excludes mandibular invasion in all likelihood.

For bone involvement of the retromolar trigone, the sensitivity of CT is approximately $50 \%$ with a negativepredictive value of $60 \%$. However, the positive-predictive value is approximately $90 \%$. Thus, while the CT scan is accurate when bone erosion is clearly identified, its negative-predictive value is unacceptably low and, therefore, is an inaccurate indicator of bone invasion at the retromolar trigone [35]. CT renders an excellent view of both the soft tissue and bone of the mandible, however, it has several limitations, the most significant being artifact caused by dental metals, which can obscure invasion of the mandibular cortex. In addition, CT may misleadingly detect defects in the cortex resulting from irregularly shaped alveoli or by or periapical disease.

In light of these shortcomings, several investigators have reported on the use of a Dentascan. The Dentascan was introduced in the early 1980 s to assist oral maxillofacial surgeons in planning for osseointegrated implants. The images are derived by reformatting standard axial CT scans in two views, panelliptical and parasagittal. This reformatting permits assessment of the buccal and lingual cortices. The diagnostic accuracy of the Dentascan for mandibular invasion is high, yielding a sensitivity of $95 \%$, and a specificity of $79 \%$ with a positive-predictive value of $87 \%$ and a negative-predictive value of $92 \%$ [36]. The Dentascan is, therefore, an accurate method for preoperative evaluation of mandibular invasion in patients with squamous cell carcinoma of the oral cavity.

Although CT and Dentascan may offer excellent methods for assessing bone, MRI offers the additional advantage of imaging soft tissue, and potentially the medullary bone space. Several studies have examined the use of MRI in assessing mandibular invasion, and it has been concluded that MRI is superior for evaluating the medullary space of the mandible, but inadequate for assessing mandibular invasion [37]. Shaha [38] examined the value of various studies, including panoramic radiographs, dental films, routine mandible films, bone scans, CT and MRI and found that CT was not very helpful mainly because of the presence of irregular alveoli and artifacts. Others have studied the combination of several diagnostic tools to assess mandibular invasion and suggested the use of a combination of CT or MRI with SPECT bone scintigraphy [39].

Clinical evaluation is essential for determining the presence of bone invasion and the optimal method of resection, marginal versus segmental [40]. Most centers consider the combination of CT or MRI and a panoramic radiography acceptable for preoperative imaging of the 
mandible and maxilla; however, the most accurate measure of bony invasion is probably determined at the time of surgery. Unless there is frank invasion of the bony cortex, periosteal stripping followed by frozen section examination at the time of surgery is often the most reliable measure of bone invasion. Recent studies have shown that technetium (Tc) $99^{\mathrm{m}}$ bone scintigraphy in the form of planar views or as SPECT provide high diagnostic accuracy for mandibular invasion by oral squamous cell carcinoma of the alveolus in both edentulous and dentate patients [41, 42].

Among all evaluations of the extent of disease in the oral cavity in relation to involvement of the mandible, it is the authors' opinion that the best investigation continues to have a routine clinical evaluation and intraoperative evaluation of the proximity of the tumor to the inner border of the mandible. However, preoperative assessment using imaging techniques for planning and preparation of an adequate surgical procedure including reconstruction will be performed in most cases. A tendency to perform multiple investigations is revealed in the current literature [43].

\section{Assessment of the neck}

For the assessment of the lymph nodes in the neck, both CT and MRI are used on a wide scale. The choice of study is often determined by the imaging modality used for evaluating the primary tumor. In general, the same technique employed for imaging of the primary tumor is used to stage the neck as well. Most studies that have compared the accuracy of CT and MRI for the assessment of the neck have found no significant difference between these two modalities [44, 45]. In studies reporting on the important issue of accuracy of CT or MRI for the assessment of the N0 neck, specificities and sensitivities of CT and MRI vary considerably [44-47], but as a rule, between 40 and $60 \%$ of all occult metastases are found using either CT or MRI.

One of the main advantages of ultrasound (US) is that it can easily be combined with fine-needle aspiration biopsy (FNAB) resulting in a specificity of $100 \%$ for the combined technique of ultrasound guided fine-needle aspiration biopsy (UGFNAB). It was demonstrated to be accurate for the evaluation of regional metastatic disease [44, 48]. Although the technique is not difficult, considerable training is required to successfully aspirate lymph nodes as small as $5 \mathrm{~mm}$ and to select the most suspicious lymph nodes from which to aspirate. In patients with a clinically negative neck, the results of UGFNAB are less impressive, as detection of lymph node metastasis by imaging techniques requires a minimum size. UGFNAB identifies clinically occult metastases with a sensitivity of no more than $48-73 \%$ [44, 47].
Fluorodeoxyglucose-positron emission tomography (FDG-PET) enables the in vivo study of tissue metabolism. FDG is an analog of glucose and its uptake reflects the metabolism of the cell, which is increased in many tumors. Disadvantages of FDG-PET are variable physiologic uptake and the lack of anatomical detail. Another disadvantage is that FDG also accumulates in inflammatory cells, such as granulocytes and hampers the differentiation between tumor and inflammatory reactions. The accuracy of the technique has been compared with conventional diagnostic methods for pretreatment evaluation, therapy response evaluation and relapse identification [49, 50].

As mentioned before, the anatomical landmarks and details on PET imaging are less well depicted than with CT or MRI. The fusion of the more functional data of PET images with the more anatomical information of CT in particular has significantly improved the interpretation of the PET images [51]. However, the diagnostic accuracy for detection of nodal metastasis does not seem to improve much by the fusion of FDG-PET with CT as compared to PET alone [52]. The main problems, limiting its accuracy remain the poor anatomical resolution of the PET technique even after fusion with low dose, non-contrast CT and the inability to reliably identify metastatic deposits under $5 \mathrm{~mm}$. As a result, the reported sensitivity of PET or PETCT detection of lymph node metastases is similar to CT and MRI and does not seem to add much to the use of these modalities [50, 52-54]. As may be expected, a lower sensitivity, ranging from 25 to $78 \%$ is reported for the N0 neck [55-58].

Recent developments to improve the ability of MRI to differentiate metastatic from benign cervical lymph nodes include diffusion-weighted imaging, dynamic contrastenhanced MRI or the use of new (lymphotropic) contrast agents as enhancers [59]. Diffusion-weighted magnetic resonance imaging (DWI MRI) may be a helpful complementary tool to distinguish tumoral from non-tumoral tissue, and a sensitivity and specificity for the detection of nodal metastasis of 98 and $88 \%$, respectively, have been reported [60].

Dynamic contrast-enhanced MRI takes advantage of the characteristics of the (metastatic) tumor as compared to normal tissue by scanning the area of interest multiple times starting before contrast, continuing through the contrast phase and ending with the post-contrast phase. The technique appears to be helpful in differentiating metastatic from non-metastatic lymph nodes [61].

Ultra-small superparamagnetic contrast agents, such as iron oxide particles (USPIO) accumulate in normal lymph nodes because the particles are taken up by macrophages in these nodes. Metastases do not take up the particles. The uptake may accumulate over 6-24 h after administration of the contrast agent. The use of these agents has been 
recently studied for the detection of nodal metastasis [62]. A sensitivity and specificity of up to 96 and $87 \%$, respectively, have been reported [63]. However, the costs and the logistical problems associated with the need for delayed imaging, 24-48 $\mathrm{h}$ after contrast injection, may prevent this technique from gaining wide acceptance although it is possible that a single acquisition could be sufficient [64]. Furthermore, the need for highly $\mathrm{T} 2$-weighted images with low-spatial resolution hampers the visibility of small metastases and will result in a low sensitivity due to falsenegative results from the presence of undetected micrometastases [64].

\section{Molecular markers as a diagnostic and prognostic tool}

Several oral cancer biomarkers have recently been discovered (alterations of p53, inactivation p16, overexpression of EGFR, etc.) Although many of these markers are thought to have potential clinical interest, few of them are being used in a clinical setting for oral cancer management.

Proteomic analysis by mass spectrometry is rapidly advancing the field of medical diagnostics because of its ability to reliably identify proteins that are minimal in concentration. These advancements have also benefited cancer biomarker research to the point where saliva is now recognized as an excellent diagnostic medium for the detection of malignant tumors of the oral cavity. Genomic and proteomic studies of oral cancer tissues, plasma, and saliva of oral cancer patients have allowed the identification of several cancer signatures with promising application for diagnosis, prognosis and treatment. In addition, methylation array analysis using saliva has allowed the identification of highly methylated gene loci with diagnostic and predictive value as a biomarker, with a sensitivity of $62-77 \%$ and a specificity of $83-100 \%$ for oral carcinoma [65]. Using subtractive proteomics, $\mathrm{Hu}$ et al. [66] revealed several salivary proteins at differential levels between the oral carcinoma patients and matched control subjects. Five candidate biomarkers were successfully validated and their combination yielded a sensitivity of $90 \%$ and specificity of $83 \%$ in detecting oral carcinoma.

As it is important to distinguish those intraepithelial lesions that will progress to invasive cancer from those that will not, it may be useful to have diagnostic tools for this purpose. Different proteins have been studied as progression markers. Thus, podoplanin is highly expressed in oral cancer and some oral premalignancies and has been found to be an independent factor for oral cancer development by multivariate analysis [67]. DNA content may also be a relevant parameter in this respect and has been found to correlate with the potential to progress to invasive cancer
[68]. Other genetic assays may be promising in distinguishing at-risk mucosal sites [69].

Nuclear expression of heterogeneous ribonucleoprotein $\mathrm{K}$ increases significantly from normal tissues to leukoplakia and malignancy, and may serve as a potential marker for early diagnosis. Variance in cytoplasmic accumulation can help in identifying a subgroup of patients with poor prognosis [70]. On the other hand, informative RNA biomarkers from the human serum transcriptome have been successfully demonstrated for oral carcinoma detection; the best combination of biomarkers yields a sensitivity of $91 \%$ and a specificity of $71 \%$ [71].

Other biomarkers are related to prognosis, as occurs with stratifin whose overexpression is correlated with reduced disease-free survival [72]. Similarly, CTTN amplification is associated with recurrence and reduced disease-specific survival and may serve as a valuable biomarker to identify patients with tumors at high risk of recurrence and poor outcome [73].

The gene expression profile of patients with oral tongue carcinoma has been analyzed, and three genes (GLUT3, HSAL2 and PACE4) have correlated with different clinical parameters, but only GLUT3 showed a prognostic value with disease free, relapse-free and overall survival [74].

Finally, markers and gene expression profiles are emerging for assessment of nodal metastasis. In the future, these markers may be important as prognostic indicators and diagnostic tools useful for decisions on elective neck treatment (a particularly important issue in oral cancer management) [75].

\section{Principles of oral cavity cancer management}

The overwhelming majority of cancers involving the oral cavity are squamous cell carcinomas. These cancers of the oral cavity may be treated with either radiation, surgery or combined therapy. Single modality therapy is usually attempted for early stage and other suitable (stages I, II and selected stage III) tumors. Multimodality therapy is usually employed for more advanced tumors.

\section{Early disease}

Superficial carcinomas of the oral cavity can be treated with equivalent excellent cure rates with either radiation therapy (interstitial or external) or surgical excision. Therefore, the choice of therapy is often based on the factors, such as patient preference, quality of life, cost, convenience and patient compliance. As surgical cures can often be achieved rapidly and with minimal morbidity, surgery is often preferred for management of early cancers of the oral cavity. Tumors involving the oral tongue can 
usually be managed through a transoral approach. Although radiotherapy is often equally effective for the treatment of early disease, the chances of long-term sequelae including xerostomia, dysphagia and osteoradionecrosis are such that the treatment of choice will be surgery in most cases. Another advantage of surgical therapy is the shorter duration of treatment; surgical therapy requires a single intervention while radiation therapy requires daily therapy for 6-7 weeks. Therefore, radiation therapy is usually reserved for those patients who are unable to undergo surgery. Another alternative treatment modality may be photodynamic therapy using laser illumination of superficial tumors after intravenous administration of a photosensitizer. However, experience with this modality is still limited [76].

\section{Advanced disease}

Advanced disease of the oral cavity is best managed with multimodality therapy. Surgery with or without reconstruction [77] coupled with preoperative or postoperative radiation therapy is often utilized for advanced disease. Although preoperative radiation has been employed in some cases to decrease the tumor mass and, therefore, facilitate "resectability" of the tumor, it is common practice to surgically resect the tumor based on the pre-radiation margins, as islands of viable tumor may persist within the initial peripheral margins. In addition, preoperative radiation is associated with a higher rate of postoperative complications. For these reasons, most centers perform surgery followed by postoperative radiation [78].

Robbins et al. [79] have employed neoadjuvant intraarterial chemotherapy and radiation followed by limited excision of the area of initial tumor. If residual cancer is found, a "completion" radical resection with wide margins around the area of the original tumor is performed. This series showed a $64 \%$ disease-specific survival and $74 \%$ locoregional control for stages II-IV disease after 56month median follow-up. However, this is single institution data that must be validated by further study.

Although primary surgical management has been advocated for advanced oral cavity cancers due to concerns of safety and efficacy of non-surgical approaches, particularly with cancers that involve bone, recent evidence suggests that primary chemoradiotherapy may be an effective treatment approach for selected patients with $\mathrm{T} 4$ lesions. Rates of locoregional control, survival and complications are comparable to those associated with primary surgical management and postoperative radiotherapy [80]. Another reason to choose chemoradiotherapy as a primary treatment may be "functional irresectability", for example, to avoid total glossectomy. However, the definition of "functional irresectability" is vague and may differ among surgeons [81].

Postoperative radiation therapy with or without concomitant chemotherapy is reserved for those cases in which the risk of recurrence is high. Defining the "high-risk" patient has been a topic of controversy. However, it is important to emphasize that the indications for postoperative radiation therapy directed to the primary site are different than the indications for postoperative radiation directed at the neck.

The goal of a surgical excision is to achieve a complete resection of the tumor with free margins. In cases where there are positive or close margins (tumor within $5 \mathrm{~mm}$ of the surgical margin), surgical re-resection is recommended if the original margins can still be properly identified and if re-resection will not induce significant functional disabilities. In cases where a re-resection is performed and evidence of microscopically positive margins remains or if reresection cannot be reliably performed, radiation therapy directed at the primary site should be considered. This is particularly the case with tumors showing perineural growth or strongly invasive growth. Brachytherapy has proven efficacious in cases with close or positive margins, particularly when re-excision cannot be easily accomplished [82].

In cases where there is neck disease staged $\mathrm{N} 2$ or greater, or when histopathological examination demonstrates unfavorable features (like capsular invasion of the nodal metastases), postoperative radiation therapy for the neck is warranted. The addition of cisplatin-based chemotherapy is indicated in the presence of positive margins in the primary tumor resection specimen, multiple lymph node involvement or ECS in the neck dissection specimen $[83,84]$.

\section{Management of tumors invading the mandible}

Tumors invading the mandible can be managed either with a marginal or a segmental resection. The decision regarding the optimal extent of mandibular resection is largely dependent on the degree of invasion. It has been suggested that tumor invasion of the periosteum or cortical bone, without invasion of the medullary cortex, can be appropriately managed with a marginal resection. Tumors that erode into the medullary canal (T4 lesions), however, require a segmental resection. It has been shown that once a tumor gains access to the medullary canal, tumor may travel through the canal within the neurovascular bundle. The inability to obtain frozen section assessment of the mandible intraoperatively represents a management dilemma because decalcification of the mandible specimen 
in preparation for definitive histopathological analysis can take as long as 2 weeks.

The periosteum is relatively resistant to cancer invasion. With the exception of the alveoli, the periosteum acts as a dense barrier to the invasion of adjacent tumor. Despite the protective periosteum, aggressive and longstanding tumors erode and invade the adjacent mandible through a variety of pathways. Two distinct histological patterns of tumor invasion have been identified. The first is referred to as infiltrative, and is characterized by finger-like projections of tumor that advance independently, invade the cancellous spaces without the intervening connective tissue layer, and possess not much osteoclastic activity. The second pattern is referred to as erosive. In contrast to the infiltrative pattern, the erosive pattern is characterized by a broad front with a connective tissue layer and vigorous osteoclastic activity. The differing significance of the erosive and infiltrative patterns has been confirmed in several reports, and it has been demonstrated that patient survival is significantly impacted by the pattern of invasion. Wong et al. [85] found that the 3-year disease-free survival for squamous cell carcinoma invading mandible with an infiltrative pattern was 30\%, while 3-year disease-free survival for the erosive pattern was $73 \%$. It has been suggested that the pattern of invasion is a reflection of the biologic aggressiveness of the tumor and may impact the approach to ablative therapy. While most tumors that invade the mandible mandate postoperative external beam radiation, it has been suggested that superficially invading tumors may not benefit from postoperative radiation. When considering the aggressive behavior of the infiltrative pattern of invasion, we recommend postoperative radiation for all patients with this pattern of bone invasion.

Tumor within the oral cavity may invade the mandible and gain entrance into the mandibular canal through several routes. Not uncommonly, tumor will travel along the surface mucosa until it approaches the attached gingiva where the tumor cells may come into contact with the periosteum of the mandible. Tumor cells demonstrate a tendency to migrate into the alveoli because this area represents a pathway of minimal resistance. In edentulous patients, tumor cells will migrate onto the occlusal surface of the alveolus and enter the mandible through dental pits, which are cortical bone defects at the location of prior dentition. Less commonly, tumor may enter the mandible through mental or mandibular canals. Finally, adjacent tumor may erode through the cortical bone directly into the mandibular canal. As mentioned earlier, this is a rare mode of invasion.

Determining the presence of bone erosion and the extent of bone invasion represents an ongoing clinical dilemma. The poor predictability associated with preoperative imaging has led many to rely on preoperative clinical assessment as the primary method for determining the presence of mandibular invasion. Several groups have studied this issue and found that clinical evaluation of mandibular bone erosion is more sensitive than radiographic evaluation; however, radiographic assessment may be more specific and provide a higher reliability index [86].

There are a few studies reviewing the impact of clinical assessment alone in determining the extent of mandibular invasion. This likely represents the difficulty in quantifying a clinical examination. However, most agree that clinical assessment for invasion is paramount. Several studies have evaluated the role of periosteal stripping as an indicator for tumor invasion of the mandible and found that periosteal stripping at the time of resection represented an accurate predictor of the presence of mandibular invasion [42]. Without clear preoperative evidence of mandibular invasion, a marginal resection followed by periosteal stripping and inspection is an adequate approach. In the event that microscopic evidence of invasion at the rim is discovered, the marginal mandibulectomy is converted into a segmental mandibulectomy.

Often, marginal mandibulectomy is performed not because of suspicion of mandibular invasion, but to obtain a wider margin of resection, and also, to achieve deeper exposure and level of resection in the floor of the mouth. In addition, marginal mandibulectomy may be helpful for intraoral resurfacing, particularly if local tissues are employed. Protrusion of uncovered bone through the suture line is thus avoided.

In summary, appropriate preoperative assessment through the combination of clinical and radiological examination is more accurate than using either modality alone. Intraoperative periosteal stripping at the time of resection, with frozen section evaluation, represents an accurate predictor of the presence of mandibular invasion and may be the only reliable method of assessment.

\section{Management of tumors invading the buccal mucosa}

Buccal cancer comprises $<10 \%$ of oral cavity cancers and when it occurs, it commonly arises from pre-existing leukoplakia [87, 88]. The principles of management of buccal cancer are no different than those of other subsites within the oral cavity, with surgical therapy as the preferred method of management. In early disease, surgical excision can usually be accomplished transorally. Tumors that invade the buccinator muscle and tumors that present with nodal disease or with poor prognostic features should be managed with postoperative irradiation. Negative surgical margins are paramount, and in an effort to achieve this goal, careful preoperative planning is essential to determine the extent of the tumor. MRI is ideal for imaging of 
the buccal mucosa and soft tissue of the masticator space. Although early tumors of the buccal mucosa commonly present as an irregular mucosal mass, more than half of buccal tumors will present as deeply invasive tumors that may track along the parotid duct, masseter muscle or into the palate. The proximity of the buccal mucosa to the parotid duct requires that the duct be traced retrograde and sampled to ensure a negative margin.

Deeply invasive lesions may break into the buccal fat pad. When this occurs, it is advisable to resect the entire fat pad because negative surgical margins in this area are difficult to confirm. The rich lymphatic network characteristic of the buccal region and the high rate of lymph node metastasis mandate that the neck be carefully evaluated and, in most cases, treated. Smaller tumors can usually be managed through a transoral approach; however, more advanced tumors may require a midline labiotomy incision.

\section{Management of tumors involving the hard palate}

Unlike other areas of the oral cavity where squamous cell carcinoma constitutes the overwhelming majority of neoplasia, the palate is rich in minor salivary glands and therefore is the frequent site of both benign and malignant salivary gland tumors. The principles of management of tumors of the palate are similar to those of the mandible; obtaining tumor-free margins is essential to achieve a good outcome. Preoperative imaging of this area is important to assess invasion of the maxillary sinus, palatal bone and the nasal vault. CT is ideal for assessing this because it offers a high-resolution image of the palatal and nasal bones. Lateral tumors may present a risk of invasion and perineural spread via the palatine or trigeminal neurovascular bundle. Pain or anesthesia may suggest nerve invasion and MRI with gadolinium may demonstrate enhancement or edema of the nerve suggesting nerve invasion. The depth of invasion will dictate the extent of the surgical resection. Superficial lesions of the palatal mucosa are best managed with a wide surgical resection including the underlying palatal periosteum. The periosteum serves as an early barrier to spread. However, as tumors become more invasive, tumors can vertically invade the nasal vault or maxillary sinus, thus requiring resection of underlying bone, and deeper (superior) structures as necessary.

Minor salivary gland tumors of the hard palate rarely metastasize to the neck and, therefore, a neck dissection is rarely warranted in the absence of demonstrable regional disease. One exception is when there is tumor erosion through the posterior or posterior lateral maxillary sinus into the ptyeryogpalatine fossa. Squamous cell carcinomas of the hard palate, when they do metastasize, have a predilection to metastasize to level I; and this region should be evaluated radiographically, or surgically by sentinel lymph node biopsy or level I dissection, particularly for T2-stage or larger tumors.

\section{Management of tumors invading the floor of mouth}

The floor of the mouth is rich in neural and vascular structures including the lingual and hypoglossal nerves, the submandibular duct, and the sublingual glands. The lack of any substantial fascial barrier means that early tumors of the floor of mouth can quickly invade in to the underlying structures and metastasize to the first echelon lymph node basin. A careful preoperative clinical examination may reveal information such as submandibular sialoadenitis or lingual atrophy that may suggest submandibular duct or hypoglossal nerve invasion, respectively. The MRI is ideal for imaging the floor of mouth because it is accurate in identifying soft tissue and perineural invasion.

Because of the density of neurovascular structures in the floor of the mouth, frequent metastasis occurs to the sublingual, submandibular and level II lymph node basins. Sessions et al. [89] reviewed 280 cases and found a significant reduction in 5-year survival in the patients with involved margins, advanced clinical tumor stage, positive nodes and tumor recurrence. These authors suggested that patients without clinically positive nodes can be observed safely for regional nodal disease because subsequent positive nodes can be effectively treated with no adverse effect on survival. Others have found that a more aggressive approach to the N0 neck is warranted and that a selective neck dissection allows for early removal of occult metastases with acceptable morbidity [90, 91]. Hicks et al. [91] found that as many as $21 \%$ of patients with T1 lesions or greater had occult metastatic disease and suggested an elective neck dissection and adjuvant radiotherapy for increased regional control for advanced tumors. However, concerning the incidence of occult metastasis, much depends on the diagnostic means that have been used for pretreatment assessment of the neck and for the detection of metastasis in the dissection specimen as mentioned earlier in this paper.

\section{Reconstruction of extensive defects}

Extensive oral cavity tumors pose a surgical challenge because of the potential for severe masticatory, speech and swallowing disturbances, and life-threatening aspiration. Patients may also suffer disfigurement following mandibulectomy, particularly when it affects the anterior segment. 
Microvascular surgery has become the preferred method for mandible reconstruction that should be performed at the time of the segmental mandible resection. Four donor sites (fibula, iliac crest, radial forearm and scapula) have become the primary sources of vascularized bone and soft tissue for the reconstruction. The fibula is the first choice for most defects, particularly those with anterior or large bony defects $[92,93]$. The use of an alternative donor site is best reserved for cases with large soft tissue and minimal bone requirements. Dental rehabilitation with osteointegrated dental implants is an important part of the reconstructive process.

Mandibular reconstructions using titanium mesh systems with particulate cancellous bone and marrow harvested from the ilium, or by means of autogenous nonvascularized iliac crest bone grafts are usually performed in a second stage and present a high recipient-site complications rate. These methods are only useful when the defect is lateral and only an extraoral approach is used [94]. The free flap success rate is close to $100 \%$, and unrestricted or soft diet can be achieved in nearly $90 \%$ of patients, whereas speech is normal or near normal in two-thirds of patients [92].

For locally advanced tumors, adequate resection necessitates near total or total glossectomy. The tongue is usually reconstructed with a rectus abdominis musculocutaneous-free flap, but postoperative functional results in terms of deglutition and speech are often poor due to the lack of mobility of the flap. Furthermore, additional resection of the epiglottis combined with total glossectomy causes severe aspiration and recurrent pneumonia. A functional "neotongue" following total glossectomy requires both soft tissue bulk and reconstruction of muscle function. To achieve this goal, the innervated transverse gracilis musculocutaneous flap has been proposed [95]. The obturator nerve to the gracilis muscle is microsurgically sutured to the hypoglossal nerve to re-innervate the gracilis muscle and the cutaneous paddle of the gracilis flap easily supplies enough bulk to replace the defect. This procedure although providing adequate glossopalatal contact and tongue movements, still does not achieve normal tongue appearance and has no intrinsic secretory capability. To circumvent this problem, in addition to the gracilis muscle flap, a free stomach flap, with mucosal surface intraorally, has been used as an added source of secretion for dry mouth with attached omentum providing adequate bulk [96].

Oral cavity defects involving several areas may not be amenable to reconstruction with a single free flap. In selected cases, multiple free flap reconstruction has been advocated to maximize quality of life even in patients with advanced cancers, particularly when the patient has received a mandibulectomy and total glossectomy [97].
Finally, for dramatic conditions in which as result of extensive surgery and postsurgical and postradiotherapy complications a patient is extremely disfigured and disabled for elementary vital functions, the recently reported technique of facial transplantation, with composite structures, may open a new frontier [98].

\section{Management of the neck}

The incidence of occult cervical metastasis in oral cavity cancer, even in early stages varies from 6 to 46\% [99], necessitating elective treatment of the neck in the majority of cases. The reason for the variance in reported incidence of metastasis may be the differences in diagnostic tools that have been used for preoperative assessment of the neck and the differences in thoroughness of finding nodal metastasis with histopathologic examination or other techniques for evaluating the neck dissection specimen. Traditional techniques of pathological analysis of neck dissections may fail to detect isolated neoplastic cells and micrometastasis $[100,101]$. There is no method of pretreatment imaging or other examination that will detect microscopic foci of metastatic disease in cervical lymph nodes. Immunohistochemical and molecular analysis of neck specimens reveals the incidence of occult metastases to be higher than revealed by light microscopy with ordinary hematoxylin and eosin staining. Occult regional metastasis may be found even in cases with small primary tumors.

\section{Neck dissection}

The neck may be treated electively by surgery or irradiation. Surgery has the advantage of permitting pathological staging of the neck, avoiding unnecessary radiation treatment and indicating cases where adjuvant therapy should be employed. As oral cavity cancer rarely metastasizes to level $\mathrm{V}$, a radical or modified radical neck dissection of all five nodal levels is not necessary. Selective neck dissection of levels I-III ("supraomohyoid neck dissection") is the procedure of choice for elective neck dissection of the neck. Most of the relatively small numbers of isolated metastasis to level IV are from primary tumors of the tongue, which are known to produce "skip metastases." Thus, an "extended supraomohyoid neck dissection" of levels I-IV is recommended by some authors for elective treatment of the neck in tongue cancer [102]. A number of recent prospective multi-institutional studies have demonstrated that sublevel IIB is rarely involved with isolated metastasis from oral cavity primary tumors, except from some tongue cancers [103-106]. Thus, it is justifiable to omit dissection of sublevel IIB in elective treatment of most cases of oral cavity cancers. Omitting sublevel IIB 
avoids additional morbidity to the accessory nerve [107]. Also, a recently published systematic review and metaanalysis of sublevel IIB metastasis in squamous cell carcinoma of the oral cavity [108] shows that isolated metastases are uncommon at this sublevel. Bilateral neck dissection should be performed in elective treatment of tumors involving midline structures and in patients with ipsilateral neck metastasis [109].

Generally, in tongue cancer, the incidence of nodal metastasis depends upon the stage of the tumor. T1, T2 and $\mathrm{T} 3$ tongue cancers are associated with 30,50 and $70 \%$ respective incidence of microscopic nodal metastasis. Selective neck dissection can be used to effectively treat clinically positive nodal disease in selected patients $[110$, 111]. The use of postoperative radiotherapy and concomitant chemotherapy should be considered in patients with pathologically positive lymph nodes, particularly in cases with adverse prognostic factors such as multiple metastatic lymph nodes or any node with extracapsular disease. Two prospective, randomized trials were reported in 2004 demonstrating improved survival and locoregional control (as well as increased toxicity) when adjuvant chemoradiotherapy was administered to patients with ECS or N2-3 disease [83, 84].

\section{Sentinel lymph node biopsy}

During the last decade, SLNB has evolved as a possible replacement for elective neck dissection with promising results $[112,113]$. The reduced number of lymph nodes can be assessed by step serial sections and immunohistochemistry [114]. The work of Goerkem et al. [21] has been discussed above.

SLNB is a technique well established for cutaneous melanoma and breast cancer, and is under extensive study by numerous groups for application to oral cavity cancer. Preoperative lymphoscintigraphy allows assessment of the individual lymphatic drainage pattern of each patient. SLNB allows accurate staging of the ipsilateral neck in clinically N0 cases, both necks in tumors crossing the midline, and the contralateral neck in tumors crossing the midline with ipsilateral positive nodes. The technique has the potential of limiting the application of elective neck dissection in $30-40 \%$ of patients who may benefit from it, reducing considerably the number of bilateral neck dissections, and sparing the morbidity and costs of elective neck dissection for those patients without regional disease who cannot benefit from neck dissection. The first promising validation studies of patients undergoing SLNB followed by elective neck dissection were published almost a decade ago by groups in Europe [114, 115]. Since then, many centers throughout the world have adopted the technique. The American College of
Surgeons Oncologic Group (ACOSOG) has recently completed a prospective validation trial and results are forthcoming [116].

Most centers in Europe have moved a step forward to observational trials. Based on the excellent results of two large series showing a neck recurrence rate after negative SLNB of $<5 \%$, a multicentric prospective observational trial has been started $[113,117]$. The accrual of patients is almost completed and first results may be expected soon.

The technique of SLNB involves preoperative injection of $[99]^{\mathrm{m}} \mathrm{Tc}$ sulfur colloid in several locations around and immediately adjacent to the tumor in the awake patient [118]. The importance of preoperative lymphoscintigraphy for the accurate detection of the sentinel nodes has been reported by Ross et al. [119]. The use of isosulfan blue dye (Lymphazurin 1\%, Hirsch Industries Inc., Richmond VA) often used in cases of melanoma, has been employed by some surgeons for oral cavity SNLB, but was not used in the ACOSOG study, and is avoided by many experienced surgeons to avoid discoloration of tissues with obscuration of important structures and mucosal margins and has other potential disadvantages, such as anaphylaxis in a small number of patients [120]. Despite some practical difficulties, the sentinel node detection rate approaches $100 \%$ once the "learning curve" of 10-20 cases has been overcome. During surgery, the gamma probe is used to scan the neck, and an incision is made over the area of highest radioactivity. All the active lymph nodes are then removed and sent to pathology for evaluation. If metastatic disease is identified, a neck dissection is performed. Otherwise, the neck can be closed. There is still controversy on the advantages and disadvantages of frozen sections. Several groups have investigated the accuracy of frozen section analysis of sentinel lymph nodes and, despite concerns regarding freezing artifacts, loss of tissue and high expenditures of labor and time, results have proven encouraging [121, 122]. The negative-predictive value of a negative SLNB with frozen section is reported to be as high as $83 \%$, with only $17 \%$ of the frozen-section negative patients having to undergo a second procedure due to false-negative frozensection examinations. In most cases, this was found to be due to isolated tumor cells or minimal micrometastatic disease [113]. If metastatic disease is identified postoperatively, a subsequent neck dissection is performed. According to the recommendations of the second international conference on sentinel node biopsy for mucosal head and neck cancer, the pathologic evaluation of the sentinel lymph nodes should be done with serial step sectioning at intervals of $150 \mu \mathrm{m}$, and in addition to staining with hematoxylin and eosin, immunohistochemical examination for cytokeratin is mandatory [123]. 
The appeal of SLNB for oral cavity cancer is that (1) it may allow patients to avoid the additional time and morbidity of a formal neck dissection, (2) it allows for a minimally invasive assessment of lymph node status in patients with low risk lesions for whom "watchful waiting" might otherwise be recommended, (3) it may detect potentially involved nodes which are outside of the expected lymphatic drainage patterns, (4) it may be an alternative for patients who refuse a neck dissection.

The chief concern regarding SLNB for oral cavity cancer is the possibility of false-negative diagnosis, although this rate has been shown to be $<5 \%$, which is in the range of elective neck dissection. In the ACOSOG validation trial, a negative-predictive value of $93 \%$ was seen on hematoxylin and eosin staining, $96 \%$ with serial step sectioning and immunohistochemistry, and $100 \%$ for $\mathrm{T} 1$ lesions [116]. Although the cohort was small, floor of mouth tumors in the ACOSOG trial had a higher rate of false negatives ( 25 vs. $8 \%$ for tongue primaries). The high likelihood of metastatic disease in patients with T3 and T4 cancers as well as the difficulties with injecting around a large tumor has limited the application of SLNB to T1 and $\mathrm{T} 2$ oral cavity cancers.

Other problems with SLNB include the fact that invariably in the neck there are multiple sentinel nodes. In addition, the "shine-through effect" (obscuration of the neck by irradiation from the primary tumor) creates some difficulties in appropriately evaluating the sentinel node during a surgical procedure. In addition, the low morbidity of selective neck dissections discourages the use of a technically demanding procedure to avoid them.

The current recommendations of the ACOSOG are that SNLB can be offered to patients who would otherwise not warrant a neck dissection ("watchful waiters"), patients who refuse neck dissection, or those on a clinical trial. In Europe, many centers have introduced SLNB as the standard of care for $\mathrm{T} 1$ and $\mathrm{T} 2$ squamous cell carcinoma of the oral cavity with "elective neck" dissection only in case of a positive SLNB (in which case, the neck dissection is no longer "elective"). Most of these centers have joined the multicentric prospective trial in order to collect data from a greater number of patients and in a shorter time. Thus, it would seem that currently the SLNB is most useful for upstaging apparently early cancers of the oral cavity, thereby identifying patients who might benefit from additional surgical or adjuvant therapy [124].

Particularly in the United States, a majority of surgeons still prefer a staging supraomohyoid neck dissection rather than SLNB, for the reasons cited above. A decision-analysis model comparing the performance of SLNB with elective neck dissection showed better outcomes with elective neck dissection over a range of micrometastasis rates from 20 to $40 \%$ [125]. Therefore, SLNB cannot be considered a standard of care at this stage [126].

"Watchful waiting"

Finally, another strategy concerning the neck in patients with small and superficial oral cancers may be a "watchful waiting" policy. In these patients, the neck will be closely observed in follow-up, usually using ultrasonography of the neck, instead of performing an elective neck dissection [127].

\section{Postoperative surveillance}

The risk of recurrence or the development of a new primary warrants close follow-up for all individuals treated for oral cavity cancer. Most recommend follow-up examinations every 2-3 months for the first year, 3-4 months for the second year, 4 months for the third year, and 5 months for the fourth and fifth years. Thereafter, patients are followed every 12 months. High-risk patients may be monitored more often while low risk patients may be monitored less frequently. Regular follow-up for over 10 years is indicated for all patients treated for cancer of the oral cavity [128].

\section{Conclusions}

Oral cavity cancers represent about one-third of head and neck malignant tumors and present unique challenges for optimal management to limit morbidity and maximize the chance for cure. The great majority are squamous cell carcinomas with a minority being mucoepidermoid or other minor salivary gland tumors. Tobacco remains the most common causative factor. HPV is strongly associated with the development of oropharyngeal cancer and a small minority of oral cavity cancers. Identification of oral cavity cancers is relatively simple given the ease of a clinical examination; therefore, screening programs and/or educational programs may be considered. The development of leukoplakia, erythroplasia, a mass or an ulcer should prompt thorough evaluation by a head and neck surgeon and most likely a transoral biopsy.

Prognosis of oral cavity cancer is generally related to the TNM classification system. However, patient-related factors, such as co-morbidity and tumor-related factors, such as perineural invasion, depth of invasion or extracapsular nodal spread are related to prognosis or may be strongly predictive of biologic behavior of the tumor as well. Initial search and follow-up surveillance for synchronous and metachronous squamous cell carcinomas may have an even greater impact on patient outcome. 
Once the diagnosis of oral cavity cancer is made, the subsequent evaluation includes imaging, though which modality to employ is controversial. CT and MRI are comparable in their ability to stage cancers of the oral cavity. MRI in particular is excellent for soft tissue evaluation and for a contrast study in patients with a contraindication to intravenous administration of iodine containing contrast. However, clinical examination both preoperative and intraoperative may still be the best way to assess tumor invasion into the mandible.

Early disease (stages I-II) is generally curable with single modality therapy. Surgery is preferable in most cases due to the simplicity of the treatment and excellent results with respect to cure and postoperative function. Advanced disease (stages III-IV) is best managed with multimodality therapy, generally with surgery followed by radiotherapy particularly for high-risk primary lesions. Adjuvant chemoradiotherapy to the neck is indicated for N2 or greater disease, or N1 disease with ECS. Primary chemoradiation may be considered in cases which are technically or "functionally" inoperable.

Tumors invading the mandible are generally managed with segmental resection. Marginal resection, indicated when suitable if it can be shown that the tumor does not invade the medullary canal, is often employed to enhance tumor margins, improve access and facilitate reconstruction. Most tumors that invade the mandible require postoperative radiotherapy for improved local control.

There is a high incidence of cervical metastases in oral cavity cancer. For all but very early primary tumors, elective treatment of the neck with either radiation or neck dissection is warranted to optimize regional control. Surgical treatment of the neck is generally preferable to radiation as it offers pathologic information, has limited morbidity, avoids the lengthy treatment regimen and morbidity of radiation. Sublevel IIB and level V are rarely involved with tumor, and therefore, elective neck dissection can generally be done without violating these regions.

SLNB for T1 and T2 cancers has been successfully evaluated in many trials all over the world. Its potential as a new standard of care is currently being widely studied in prospective clinical trials.

Open Access This article is distributed under the terms of the Creative Commons Attribution Noncommercial License which permits any noncommercial use, distribution, and reproduction in any medium, provided the original author(s) and source are credited.

\section{References}

1. Cooper JS, Porter K, Mallin K, Hoffman HT, Weber RS, Ang KK, Gay EG, Langer CJ (2009) National Cancer Database report on cancer of the head and neck: 10-year update. Head Neck 31:748-758

2. de Camargo Cancela M, Voti L, Guerra-Yi M, Chapuis F, Mazuir M, Curado MP (2010) Oral cavity cancer in developed and in developing countries: population-based incidence. Head Neck (in press)

3. Hashibe M, Brennan P, Chuang SC, Boccia S, Castellsague X, Chen C, Curado MP, Dal Maso L, Daudt AW, Fabianova E, Fernandez L, Wünsch-Filho V, Franceschi S, Hayes RB, Herrero R, Kelsey K, Koifman S, La Vecchia C, Lazarus P, Levi F, Lence JJ, Mates D, Matos E, Menezes A, McClean MD, Muscat J, Eluf-Neto J, Olshan AF, Purdue M, Rudnai P, Schwartz SM, Smith E, Sturgis EM, Szeszenia-Dabrowska N, Talamini R, Wei Q, Winn DM, Shangina O, Pilarska A, Zhang ZF, Ferro G, Berthiller J, Boffetta P (2009) Interaction between tobacco and alcohol use and the risk of head and neck cancer: pooled analysis in the International Head and Neck Cancer Epidemiology Consortium. Cancer Epidemiol Biomarkers Prev 18:541-550

4. Hennessey PT, Westra WH, Califano JA (2009) Human papillomavirus and head and neck squamous cell carcinoma: recent evidence and clinical implications. J Dent Res 88:300-306

5. Chaturvedi AK, Engels EA, Anderson WF, Gillison ML (2008) Incidence trends for human papilloma virus-related and -unrelated oral squamous cell carcinomas in the United States. J Clin Oncol 26:612-619

6. Smeets SJ, Hesselink AT, Speel EJ, Haesevoets A, Snijders PJ, Pawlita M, Meijer CJ, Braakhuis BJ, Leemans CR, Brakenhoff RH (2007) A novel algorithm for reliable detection of human papillomavirus in paraffin embedded head and neck cancer specimen. Int J Cancer 121:2465-2472

7. Sikora AG, Morris LG, Sturgis EM (2009) Bidirectional association of anogenital and oral cavity/pharyngeal carcinomas in men. Arch Otolaryngol Head Neck Surg 135:402-405

8. Velly AM, Franco EL, Schlecht N, Pintos J, Kowalski LP, Oliveira BV, Curado MP (1998) Relationship between dental factors and risk of upper aerodigestive tract cancer. Oral Oncol 34:284-291

9. Molinolo AA, Amornphimoltham P, Squarize CH, Castilho RM, Patel V, Gutkind JS (2009) Dysregulated molecular networks in head and neck carcinogenesis. Oral Oncol 45:324-334

10. Ho T, Wei Q, Sturgis EM (2007) Epidemiology of carcinogen metabolism genes and risk of squamous cell carcinoma of the head and neck. Head Neck 29:682-699

11. Rapidis AD, Gullane P, Langdon JD, Lefebvre JL, Scully C, Shah JP (2009) Major advances in the knowledge and understanding of the epidemiology, aetiopathogenesis, diagnosis, management and prognosis of oral cancer. Oral Oncol 45:299300

12. Garnis C, Chari R, Buys TP, Zhang L, Ng RT, Rosin MP, Lam WL (2009) Genomic imbalances in precancerous tissues signal oral cancer risk. Mol Cancer 23:8-50

13. Fleskens S, Slootweg P (2009) Grading systems in head and neck dysplasia: their prognostic value, weaknesses and utility. Head Neck Oncol 1:11

14. Waldron CA, Shafer WG (1975) Leukoplakia revisited: a clinicopathologic study 3256 oral leukoplakias. Cancer 36:13861392

15. Takes RP, Rinaldo A, Silver CE, Piccirillo JF, Haigentz M Jr, Suárez C, Vander Poorten V, Hermans R, Rodrigo JP, Devaney KO, Ferlito A (2010) The future of the TNM classification and staging system in head and neck cancer. Head Neck (in press)

16. Yuen AP, Lam KY, Wei WI, Lam KY, Ho CM, Chow TL, Yuen WF (2000) A comparison of the prognostic significance of tumor diameter, length, width, thickness, area, volume, and clinicopathological features of oral tongue carcinoma. Am J Surg 180:139-143 
17. Asakage T, Yokose T, Mukai K, Tsugane S, Tsubono Y, Asai M, Ebihara S (1998) Tumor thickness predicts cervical metastasis in patients with stage I/II carcinoma of the tongue. Cancer 82:1443-1448

18. Fukano H, Matsuura H, Hasegawa Y, Nakamura S (1997) Depth of invasion as a predictive factor for cervical lymph node metastasis in tongue carcinoma. Head Neck 19:205-210

19. Patel RS, Clark JR, Dirven R, Wyten R, Gao K, O'Brien CJ (2009) Prognostic factors in the surgical treatment of patients with oral carcinoma. ANZ J Surg 79:19-22

20. Ambrosch P, Brinck U (1996) Detection of nodal micrometastases in head and neck cancer by serial sectioning and immunostaining. Oncology (Williston Park) 10:1221-1226

21. Goerkem M, Braun J, Stoeckli SJ (2010) Evaluation of clinical and histomorphological parameters as potential predictors of occult metastases in sentinel lymph nodes of early squamous cell carcinomas of the oral cavity. Ann Surg Oncol (in press)

22. Bilde A, von Buchwald C, Therkildsen MH, Mortensen J, Kirkegaard J, Charabi B, Specht L (2008) Need for intensive histopathologic analysis to determine lymph node metastases when using sentinel node biopsy in oral cancer. Laryngoscope 118:408-414

23. Alkureishi LW, Ross GL, Shoaib T, Soutar DS, Robertson AG, Sorensen JA, Thomsen J, Krogdahl A, Alvarez J, Barbier L, Santamaria J, Poli T, Sesenna E, Kovács AF, Grünwald F, Barzan L, Sulfaro S, Alberti F (2008) Does tumor depth affect nodal upstaging in squamous cell carcinoma of the head and neck? Laryngoscope 118:629-634

24. Alvi A, Johnson JT (1996) Extracapsular spread in the clinically negative neck (N0): implications and outcome. Otolaryngol Head Neck Surg 114:65-70

25. Greenberg JS, Fowler R, Gomez J, Mo V, Roberts D, El Naggar AK, Myers JN (2003) Extent of extracapsular spread: a critical prognosticator in oral tongue cancer. Cancer 97:1464-1470

26. Ferlito A, Rinaldo A, Devaney KO, MacLennan K, Myers JN, Petruzzelli GJ, Shaha AR, Genden EM, Johnson JT, de Carvalho MB, Myers EN (2002) Prognostic significance of microscopic and macroscopic extracapsular spread from metastatic tumor in the cervical lymph nodes. Oral Oncol 38:747-751

27. Woolgar JA, Vaughan ED, Scott J, Brown JS (1994) Pathological findings in clinically false-negative and false-positive neck dissections for oral carcinoma. Ann R Coll Surg Engl 76:237-244

28. Brandwein-Gensler M, Teixeira MS, Lewis CM, Lee B, Rolnitzky L, Hille JJ, Genden E, Urken ML, Wang BY (2005) Oral squamous cell carcinoma: histologic risk assessment, but not margin status, is strongly predictive of local disease-free and overall survival. Am J Surg Pathol 29:167-178

29. Poate TW, Buchanan JA, Hodgson TA, Speight PM, Barrett AW, Moles DR, Scully C, Porter SR (2004) An audit of the efficacy of the oral brush biopsy technique in a specialist Oral Medicine unit. Oral Oncol 40:829-834

30. Svirsky JA, Burns JC, Carpenter WM, Cohen DM, Bhattacharyya I, Fantasia JE, Lederman DA, Lynch DP, Sciubba JJ, Zunt SL (2002) Comparison of computer-assisted brush biopsy results with follow up scalpel biopsy and histology. Gen Dent 50:500-503

31. Upile T, Jerjes W, Sterenborg HJ, El-Naggar AK, Sandison A, Witjes MJ, Biel MA, Bigio I, Wong BJ, Gillenwater A, Macrobert AJ, Robinson DJ, Betz CS, Stepp H, Bolotine L, McKenzie G, Mosse CA, Barr H, Chen Z, Berg K, D'Cruz AK, Stone N, Kendall C, Fisher S, Leunig A, Olivo M, RichardsKortum R, Soo KC, Bagnato V, Choo-Smith LP, Svanberg K, Tan IB, Wilson BC, Wolfsen H, Yodh AG, Hopper C (2009) Head and neck optical diagnostics: vision of the future of surgery. Head Neck Oncol 1:25
32. Leslie A, Fyfe E, Guest P, Goddard P, Kabala JE (1999) Staging of squamous cell carcinoma of the oral cavity and oropharynx: a comparison of MRI and CT in T- and N-staging. J Comput Assist Tomogr 23:43-49

33. van den Brekel MW, Runne RW, Smeele LE, Tiwari RM, Snow GB, Castelijns JA (1998) Assessment of tumour invasion into the mandible: the value of different imaging techniques. Eur Radiol 8:1552-1557

34. Imola MJ, Gapany M, Grund F, Djalilian H, Fehling S, Adams G (2001) Technetium 99m single positron emission computed tomography scanning for assessing mandible invasion in oral cavity cancer. Laryngoscope 111:373-381

35. Lane AP, Buckmire RA, Mukherji SK, Pillsbury HC 3rd, Meredith SD (2000) Use of computed tomography in the assessment of mandibular invasion in carcinoma of the retromolar trigone. Otolaryngol Head Neck Surg 122:673-677

36. Brockenbrough JM, Petruzzelli GJ, Lomasney L (2003) DentaScan as an accurate method of predicting mandibular invasion in patients with squamous cell carcinoma of the oral cavity. Arch Otolaryngol Head Neck Surg 129:113-117

37. Tsue TT, McCulloch TM, Girod DA, Couper DJ, Weymuller EA Jr, Glenn MG (1994) Predictors of carcinomatous invasion of the mandible. Head Neck 16:116-126

38. Shaha AR (1991) Preoperative evaluation of the mandible in patients with carcinoma of the floor of mouth. Head Neck 13:398-402

39. Van Cann EM, Koole R, Oyen WJ, de Rooy JW, de Wilde PC, Slootweg PJ, Schipper M, Merkx MA, Stoelinga PJ (2008) Assessment of mandibular invasion of squamous cell carcinoma by various modes of imaging: constructing a diagnostic algorithm. Int J Oral Maxillofac Surg 37:535-541

40. Pandey M, Rao LP, Das SR (2009) Predictors of mandibular involvement in cancers of the oromandibular region. J Oral Maxillofac Surg 67:1069-1073

41. Shaw RJ, Brown JS, Woolgar JA, Lowe D, Rogers SN, Vaughan ED (2004) The influence of the pattern of mandibular invasion on recurrence and survival in oral squamous cell carcinoma. Head Neck 26:861-869

42. Brown JS, Lowe D, Kalavrezos N, D'Souza J, Magennis P, Woolgar J (2002) Patterns of invasion and routes of tumor entry into the mandible by oral squamous cell carcinoma. Head Neck 24:370-383

43. Brown JS, Lewis-Jones H (2001) Evidence for imaging the mandible in the management of oral squamous cell carcinoma: a review. Br J Oral Maxillofac Surg 39:411-418

44. van den Brekel MW, Castelijns JA, Stel HV, Golding RP, Meyer CJ, Snow GB (1993) Modern imaging techniques and ultrasound-guided aspiration cytology for the assessment of neck node metastases: a prospective comparative study. Eur Arch Otorhinolaryngol 250:11-17

45. Curtin HD, Ishwaran H, Mancuso AA, Dalley RW, Caudry DJ, McNeil BJ (1998) Comparison of CT and MR imaging in staging of neck metastases. Radiology 207:123-130

46. Atula TS, Varpula MJ, Kurki TJ, Klemi PJ, Grénman R (1997) Assessment of cervical lymph node status in head and neck cancer patients: palpation, computed tomography and low field magnetic resonance imaging compared with ultrasound-guided fine-needle aspiration cytology. Eur J Radiol 25:152-161

47. Takes RP, Righi P, Meeuwis CA, Manni JJ, Knegt P, Marres HA, Spoelstra HA, de Boer MF, van der Mey AG, Bruaset I, Ball V, Weisberger E, Radpour S, Kruyt RH, Joosten FB, Laméris JS, van Oostayen JA, Kopecky K, Caldemeyer K, Henzen-Logmans SC, Wiersma-van Tilburg JM, Bosman FT, van Krieken JH, Hermans J, Baatenburg de Jong RJ (1998) The value of ultrasound with ultrasound-guided fine-needle aspiration biopsy compared to computed tomography in the detection 
of regional metastases in the clinically negative neck. Int $\mathrm{J}$ Radiat Oncol Biol Phys 40:1027-1032

48. Baatenburg de Jong RJ, Rongen RJ, Verwoerd CD, van Overhagen H, Laméris JS, Knegt P (1991) Ultrasound-guided fineneedle aspiration biopsy of neck nodes. Arch Otolaryngol Head Neck Surg 117:402-404

49. Braams JW, Pruim J, Nikkels PG, Roodenburg JL, Vaalburg W, Vermey A (1996) Nodal spread of squamous cell carcinoma of the oral cavity detected with PET-tyrosine, MRI and CT. J Nucl Med 37:897-901

50. Stuckensen T, Kovács AF, Adams S, Baum RP (2000) Staging of the neck in patients with oral cavity squamous cell carcinomas: a prospective comparison of PET, ultrasound, CT and MRI. J Craniomaxillofac Surg 28:319-324

51. Branstetter BF 4th, Blodgett TM, Zimmer LA, Snyderman CH, Johnson JT, Raman S, Meltzer CC (2005) Head and neck malignancy: is PET/CT more accurate than PET or CT alone? Radiology 235:580-586

52. Roh JL, Yeo NK, Kim JS, Lee JH, Cho KJ, Choi SH, Nam SY, Kim SY (2007) Utility of 2-[18F] fluoro-2-deoxy-D-glucose positron emission tomography and positron emission tomography/computed tomography imaging in the preoperative staging of head and neck squamous cell carcinoma. Oral Oncol 43:887893

53. Di Martino E, Nowak B, Hassan HA, Hausmann R, Adam G, Buell U, Westhofen M (2000) Diagnosis and staging of head and neck cancer: a comparison of modern imaging modalities (positron emission tomography, computed tomography, color-coded duplex sonography) with panendoscopic and histopathologic findings. Arch Otolaryngol Head Neck Surg 126:1457-1461

54. Pohar S, Brown R, Newman N, Koniarczyk M, Hsu J, Feiglin D (2007) What does PET imaging add to conventional staging of head and neck cancer patients? Int J Radiat Oncol Biol Phys 68:383-387

55. Schöder H, Carlson DL, Kraus DH, Stambuk HE, Gönen M, Erdi YE, Yeung HW, Huvos AG, Shah JP, Larson SM, Wong RJ (2006) 18F-FDG PET/CT for detecting nodal metastases in patients with oral cancer staged N0 by clinical examination and CT/MRI. J Nucl Med 47:755-762

56. Ng SH, Yen TC, Chang JT, Chan SC, Ko SF, Wang HM, Lee LY, Kang CJ, Wong AM, Liao CT (2006) Prospective study of [18F]fluorodeoxyglucose positron emission tomography and computed tomography and magnetic resonance imaging in oral cavity squamous cell carcinoma with palpably negative neck. J Clin Oncol 24:4371-4376

57. Brouwer J, de Bree R, Comans EF, Castelijns JA, Hoekstra OS, Leemans CR (2004) Positron emission tomography using [18F]fluorodeoxyglucose (FDG-PET) in the clinically negative neck: is it likely to be superior? Eur Arch Otorhinolaryngol 261:479-483

58. Stoeckli SJ, Steinert H, Pfaltz M, Schmid S (2002) Is there a role for positron emission tomography with $18 \mathrm{~F}$-fluorodeoxyglucose in the initial staging of nodal negative oral and oropharyngeal squamous cell carcinoma. Head Neck 24:345-349

59. Misselwitz B (2006) MR contrast agents in lymph node imaging. Eur J Radiol 58:375-382

60. Abdel Razek AA, Soliman NY, Elkhamary S, Alsharaway MK, Tawfik A (2006) Role of diffusion-weighted MR imaging in cervical lymphadenopathy. Eur Radiol 16:1468-1477

61. Fischbein NJ, Noworolski SM, Henry RG, Kaplan MJ, Dillon WP, Nelson SJ (2003) Assessment of metastatic cervical adenopathy using dynamic contrast-enhanced MR imaging. AJNR Am J Neuroradiol 24:301-311

62. Mack MG, Balzer JO, Straub R, Eichler K, Vogl TJ (2002) Superparamagnetic iron oxide-enhanced MR imaging of head and neck lymph nodes. Radiology 222:239-244
63. Anzai Y, Piccoli CW, Outwater EK, Stanford W, Bluemke DA, Nurenberg P, Saini S, Maravilla KR, Feldman DE, Schmiedl UP, Brunberg JA, Francis IR, Harms SE, Som PM, Tempany CM (2003) Evaluation of neck and body metastases to nodes with ferumoxtran 10-enhanced MR imaging: phase III safety and efficacy study. Radiology 228:777-788

64. Sigal R, Vogl T, Casselman J, Moulin G, Veillon F, Hermans R, Dubrulle F, Viala J, Bosq J, Mack M, Depondt M, Mattelaer C, Petit P, Champsaur P, Riehm S, Dadashitazehozi Y, de Jaegere T, Marchal G, Chevalier D, Lemaitre L, Kubiak C, Helmberger R, Halimi P (2002) Lymph node metastases from head and neck squamous cell carcinoma: MR imaging with ultrasmall superparamagnetic iron oxide particles (Sinerem MR) - results of a phase-III multicenter clinical trial. Eur Radiol 12:1104-1113

65. Viet CT, Schmidt BL (2008) Methylation array analysis of preoperative and postoperative saliva DNA in oral cancer patients. Cancer Epidemiol Biomarkers Prev 17:3603-3611

66. Hu S, Arellano M, Boontheung P, Wang J, Zhou H, Jiang J, Elashoff D, Wei R, Loo JA, Wong DT (2008) Salivary proteomics for oral cancer biomarker discovery. Clin Cancer Res 14:6246-6252

67. Kawaguchi H, El-Naggar AK, Papadimitrakopoulou V, Ren H, Fan YH, Feng L, Lee JJ, Kim E, Hong WK, Lippman SM, Mao L (2008) Podoplanin: a novel marker for oral cancer risk in patients with oral premalignancy. J Clin Oncol 26:354-360

68. Torres-Rendon A, Stewart R, Craig GT, Wells M, Speight PM (2009) DNA ploidy analysis by image cytometry helps to identify oral epithelial dysplasias with a high risk of malignant progression. Oral Oncol 45:468-473

69. Bremmer JF, Braakhuis BJ, Brink A, Broeckaert MA, Beliën JA, Meijer GA, Kuik DJ, Leemans CR, Bloemena E, van der Waal I, Brakenhoff RH (2008) Comparative evaluation of genetic assays to identify oral pre-cancerous fields. J Oral Pathol Med 37:599_ 606

70. Matta A, Tripathi SC, DeSouza LV, Grigull J, Kaur J, Chauhan SS, Srivastava A, Thakar A, Shukla NK, Duggal R, DattaGupta S, Ralhan R, Michael Siu KW (2009) Heterogeneous ribonucleoprotein $\mathrm{K}$ is a marker of oral leukoplakia and correlates with poor prognosis of squamous cell carcinoma. Int $\mathrm{J}$ Cancer 125:1398-1406

71. Li Y, Elashoff D, Oh M, Sinha U, St John MA, Zhou X, Abemayor E, Wong DT (2006) Serum circulating human mRNA profiling and its utility for oral cancer detection. J Clin Oncol 24:1754-1760

72. Matta A, DeSouza LV, Shukla NK, Gupta SD, Ralhan R, Siu KW (2008) Prognostic significance of head-and-neck cancer biomarkers previously discovered and identified using iTRAQlabeling and multidimensional liquid chromatography-tandem mass spectrometry. J Proteome Res 7:2078-2087

73. Rodrigo JP, García-Carracedo D, García LA, Menéndez S, Allonca E, González MV, Fresno MF, Suárez C, García-Pedrero JM (2009) Distinctive clinicopathological associations of amplification of the cortactin gene at 11q13 in head and neck squamous cell carcinomas. J Pathol 217:516-523

74. Estilo CL, O-charoenrat P, Talbot S, Socci ND, Carlson DL, Ghossein R, Williams T, Yonekawa Y, Ramanathan Y, Boyle JO, Kraus DH, Patel S, Shaha AR, Wong RJ, Huryn JM, Shah JP, Singh B (2009) Oral tongue cancer gene expression profiling: identification of novel potential prognosticators by oligonucleotide microarray analysis. BMC Cancer 9:11

75. Roepman P, Wessels LF, Kettelarij N, Kemmeren P, Miles AJ, Lijnzaad P, Tilanus MG, Koole R, Hordijk GJ, van der Vliet PC, Reinders MJ, Slootweg PJ, Holstege FC (2005) An expression profile for diagnosis of lymph node metastases from primary head and neck squamous cell carcinomas. Nat Genet 37:182186 
76. Nyst HJ, Tan IB, Stewart FA, Balm AJ (2009) Is photodynamic therapy a good alternative to surgery and radiotherapy in the treatment of head and neck cancer? Photodiagnosis Photodyn Ther 6:3-11

77. de Bree R, Rinaldo A, Genden EM, Suárez C, Rodrigo JP, Fagan JJ, Kowalski LP, Ferlito A, Leemans CR (2008) Modern reconstruction techniques for oral and pharyngeal defects after tumor resection. Eur Arch Otorhinolaryngol 265:1-9

78. Klug C, Berzaczy D, Voracek M, Millesi W (2008) Preoperative chemoradiotherapy in the management of oral cancer: a review. J Craniomaxillofac Surg 36:75-88

79. Robbins KT, Samant S, Vieira F, Kumar P (2004) Presurgical cytoreduction of oral cancer using intra-arterial cisplatin and limited concomitant radiation therapy (Neo-RADPLAT). Arch Otolaryngol Head Neck Surg 130:28-32

80. Cohen EE, Baru J, Huo D, Haraf DJ, Crowley M, Witt ME, Blair EA, Weichselbaum RR, Rosen F, Vokes EE, Stenson K (2009) Efficacy and safety of treating T4 oral cavity tumors with primary chemoradiotherapy. Head Neck 31:1013-1021

81. Kreeft A, Tan IB, van den Brekel MW, Hilgers FJ, Balm AJ (2009) The surgical dilemma of 'functional inoperability' in oral and oropharyngeal cancer: current consensus on operability with regard to functional results. Clin Otolaryngol 34:140-146

82. Beitler JJ, Smith RV, Silver CE, Quish A, Deore SM, Mullokandov E, Fontenla DP, Wadler S, Hayes MK, Vikram B (1998) Close or positive margins after surgical resection for the head and neck cancer patient: the addition of brachytherapy improves local control. Int J Radiat Oncol Biol Phys 40:313-317

83. Cooper JS, Pajak TF, Forastiere AA, Jacobs J, Campbell BH, Saxman SB, Kish JA, Kim HE, Cmelak AJ, Rotman M, Machtay M, Ensley JF, Chao KS, Schultz CJ, Lee N, Fu K, Radiation Therapy Oncology Group 9501/Intergroup (2004) Postoperative concurrent radiotherapy and chemotherapy for high-risk squamous-cell carcinoma of the head and neck. N Engl J Med 350:1937-1944

84. Bernier J, Domenge C, Ozsahin M, Matuszewska K, Lefèbvre $\mathrm{JL}$, Greiner RH, Giralt J, Maingon P, Rolland F, Bolla M, Cognetti F, Bourhis J, Kirkpatrick A, van Glabbeke M, European Organization for Research and Treatment of Cancer Trial 22931 (2004) Postoperative irradiation with or without concomitant chemotherapy for locally advanced head and neck cancer. N Engl J Med 350:1945-1952

85. Wong RJ, Keel SB, Glynn RJ, Varvares MA (2000) Histological pattern of mandibular invasion by oral squamous cell carcinoma. Laryngoscope 110:65-72

86. Werning JW, Byers RM, Novas MA, Roberts D (2001) Preoperative assessment for and outcomes of mandibular conservation surgery. Head Neck 23:1024-1030

87. Holmstrup P, Thorn JJ, Rindum J, Pindborg JJ (1988) Malignant development of lichen planus-affected oral mucosa. J Oral Pathol 17:219-225

88. Vegers JW, Snow GB, van der Waal I (1979) Squamous cell carcinoma of the buccal mucosa: a review of 85 cases. Arch Otolaryngol 105:192-195

89. Sessions DG, Spector GJ, Lenox J, Parriott S, Haughey B, Chao C, Marks J, Perez C (2000) Analysis of treatment results for floor-of-mouth cancer. Laryngoscope 110:1764-1772

90. McGuirt WF Jr, Johnson JT, Myers EN, Rothfield R, Wagner R (1995) Floor of mouth carcinoma: the management of the clinically negative neck. Arch Otolaryngol Head Neck Surg 121:278-282

91. Hicks WL Jr, Loree TR, Garcia RI, Maamoun S, Marshall D, Orner JB, Bakamjian VY, Shedd DP (1997) Squamous cell carcinoma of the floor of mouth: a 20 -year review. Head Neck 19:400-405
92. Cordeiro PG, Disa JJ, Hidalgo DA, Hu QY (1999) Reconstruction of the mandible with osseous free flaps: a 10-year experience with 150 consecutive patients. Plast Reconstr Surg 104:1314-1320

93. Schrag C, Chang YM, Tsai CY, Wei FC (2006) Complete rehabilitation of the mandible following segmental resection. J Surg Oncol 94:538-545

94. van Gemert JT, van Es RJ, Van Cann EM, Koole R (2009) Nonvascularized bone grafts for segmental reconstruction of the mandible - a reappraisal. J Oral Maxillofac Surg 67:1446-1452

95. Yousif NJ, Dzwierzynski WW, Sanger JR, Matloub HS, Campbell BH (1999) The innervated gracilis musculocutaneous flap for total tongue reconstruction. Plast Reconstr Surg 104:916-921

96. Sharma M, Iyer S, Kuriakose MA, Vijayaraghavan S, Arun P, Sudhir VR, Chatni SS, Sharan R (2009) Functional reconstruction of near total glossectomy defects using composite gastro omental-dynamic gracilis flaps. J Plast Reconstr Aesthet Surg 62:1277-1280

97. Hanasono MM, Weinstock YE, Yu P (2008) Reconstruction of extensive head and neck defects with multiple simultaneous free flaps. Plast Reconstr Surg 122:1739-1746

98. Siemionow M, Papay F, Alam D, Bernard S, Djohan R, Gordon C, Hendrickson M, Lohman R, Eghtesad B, Coffman K, Kodish E, Paradis C, Avery R, Fung J (2009) Near-total human face transplantation for a severely disfigured patient in the USA. Lancet 374:203-209

99. Capote A, Escorial V, Muñoz-Guerra MF, Rodríguez-Campo FJ, Gamallo C, Naval L (2007) Elective neck dissection in earlystage oral squamous cell carcinoma-does it influence recurrence and survival? Head Neck 29:3-11

100. Ferlito A, Shaha AR, Rinaldo A (2002) The incidence of lymph node micrometastases in patients pathologically staged N0 in cancer of oral cavity and oropharynx. Oral Oncol 38:3-5

101. Ferlito A, Rinaldo A, Devaney KO, Nakashiro K, Hamakawa H (2008) Detection of lymph node micrometastases in patients with squamous carcinoma of the head and neck. Eur Arch Otorhinolaryngol 265:1147-1153

102. Byers RM, Weber RS, Andrews T, McGill D, Kare R, Wolf P (1997) Frequency and therapeutic implications of "skip metastases" in the neck from squamous carcinoma of the oral tongue. Head Neck 19:14-19

103. Lim YC, Song MH, Kim SC, Kim KM, Choi EC (2004) Preserving level IIb lymph nodes in elective supraomohyoid neck dissection for oral cavity squamous cell carcinoma. Arch Otolaryngol Head Neck Surg 130:1088-1091

104. Elsheikh MN, Mahfouz ME, Elsheikh E (2005) Level IIb lymph nodes metastasis in elective supraomohyoid neck dissection for oral cavity squamous cell carcinoma: a molecular-based study. Laryngoscope 115:1636-1640

105. Bolzoni Villaret A, Piazza C, Peretti G, Calabrese L, Ansarin M, Chiesa F, Pellini R, Spriano G, Nicolai P (2007) Multicentric prospective study on the prevalence of sublevel IIb metastases in head and neck cancer. Arch Otolaryngol Head Neck Surg 133:897-903

106. Paleri V, Kumar Subramaniam S, Oozeer N, Rees G, Krishnan S (2008) Dissection of the submuscular recess (sublevel IIb) in squamous cell cancer of the upper aerodigestive tract: prospective study and systematic review of the literature. Head Neck 30:194-200

107. Ferlito A, Silver CE, Suárez C, Rinaldo A (2007) Preliminary multi-institutional prospective pathologic and molecular studies support preservation of sublevel IIB and level IV for laryngeal squamous carcinoma with clinically negative neck. Eur Arch Otorhinolaryngol 264:111-114 
108. Lea J, Bachar G, Sawka AM, Lakra DC, Gilbert RW, Irish JC, Brown DH, Gullane PJ, Goldstein DP (2010) Metastases to level IIb in squamous cell carcinoma of the oral cavity: a systematic review and meta-analysis. Head Neck 32:184-190

109. Ferlito A, Silver CE, Rinaldo A (2009) Elective management of the neck in oral cavity squamous carcinoma: current concepts supported by prospective studies. Br J Oral Maxillofac Surg 47:5-9

110. Ferlito A, Rinaldo A, Silver CE, Gourin CG, Shah JP, Clayman GL, Kowalski LP, Shaha AR, Robbins KT, Suárez C, Leemans CR, Ambrosch P, Medina JE, Weber RS, Genden EM, Pellitteri PK, Werner JA, Myers EN (2006) Elective and therapeutic selective neck dissection. Oral Oncol 42:14-25

111. Patel RS, Clark JR, Gao K, O'Brien CJ (2008) Effectiveness of selective neck dissection in the treatment of the clinically positive neck. Head Neck 30:1231-1236

112. Stoeckli SJ, Alkureishi LW, Ross GL (2009) Sentinel node biopsy for early oral and oropharyngeal squamous cell carcinoma. Eur Arch Otorhinolaryngol 266:787-793

113. Stoeckli SJ (2007) Sentinel node biopsy for oral and oropharyngeal squamous cell carcinoma of the head and neck. Laryngoscope 117:1539-1551

114. Stoeckli SJ, Steinert H, Pfaltz M, Schmid S (2001) Sentinel lymph node evaluation in squamous cell carcinoma of the head and neck. Otolaryngol Head Neck Surg 125:221-226

115. Shoaib T, Soutar DS, Prosser JE, Dunaway DJ, Gray HW, McCurrach GM, Bessent RG, Robertson AG, Oliver R, MacDonald DG (1999) A suggested method for sentinel node biopsy in squamous cell carcinoma of the head and neck. Head Neck 21:728-733

116. Civantos FJ, Zitsch R, Schuller D, Agrawal A, Smith R, Nason R, Petruzelli G, Gourin C, Yarbrough W, Myers J (2006) Sentinel lymph node biopsy for oral cancer: a multi-institutional validation trial. Arch Otolaryngol Head Neck Surg 132:839-840

117. Ross GL, Soutar DS, MacDonald DG, Shoaib T, Camilleri I, Roberton AG, Sorensen JA, Thomsen J, Grupe P, Alvarez J, Barbier L, Santamaria J, Poli T, Massarelli O, Sesenna E, Kovács AF, Grünwald F, Barzan L, Sulfaro S, Alberti F (2004) Sentinel node biopsy in head and neck cancer: preliminary results of a multicenter trial. Ann Surg Oncol 11:690-696

118. Civantos FJ (2010) Sentinel lymph node biopsy for head and neck cancer. In: Ferlito A, Robbins KT, Silver CE (eds) Neck dissection-management of regional disease in head and neck cancer. Plural Publishing, San Diego, pp 81-95

119. Ross GL, Soutar DS, Shoaib T, Sato E, Hyodo I, Ogawa T, Nakashima T, Yatabe Y (2002) The ability of lymphoscintigraphy to direct sentinel node biopsy in the clinically N0 neck for patients with head and neck squamous cell carcinoma. Br J Radiol 75:950-958

120. Longnecker SM, Guzzardo MM, Van Voris LP (1985) Lifethreatening anaphylaxis following subcutaneous administration of isosulfan blue 1\%. Clin Pharm 4:219-221

121. Terada A, Hasegawa Y, Goto M, Sato E, Hyodo I, Ogawa T, Nakashima T, Yatabe Y (2006) Sentinel lymph node radiolocalization in clinically negative neck oral cancer. Head Neck 28:114-120

122. Tschopp L, Nuyens M, Stauffer E, Krause T, Zbären P (2005) The value of frozen section analysis of the sentinel lymph node in clinically N0 squamous cell carcinoma of the oral cavity and oropharynx. Otolaryngol Head Neck Surg 132:99-102

123. Stoeckli SJ, Pfaltz M, Ross GL, Steiner HC, MacDonald DG, Wittekind C, Soutar DS (2005) The second international conference on sentinel node biopsy in mucosal head and neck cancer. Ann Surg Oncol 12:919-924

124. Ross G, Shoaib T, Soutar DS, Camilleri IG, Gray HW, Bessent RG, Robertson AG, MacDonald DG (2002) The use of sentinel node biopsy to upstage the clinically N0 neck in head and neck cancer. Arch Otolaryngol Head Neck Surg 128:1287-1291

125. Paleri V, Rees G, Arullendran P, Shoaib T, Krishman S (2005) Sentinel node biopsy in squamous cell cancer of the oral cavity and oral pharynx: a diagnostic meta-analysis. Head Neck 27:739-747

126. Devaney KO, Rinaldo A, Rodrigo JP, Ferlito A (2006) Sentinel node biopsy and head and neck tumors: where do we stand today? Head Neck 28:1122-1131

127. Nieuwenhuis EJ, Castelijns JA, Pijpers R, van den Brekel MW, Brakenhoff RH, van der Waal I, Snow GB, Leemans CR (2002) Wait-and-see policy for the N0 neck in early-stage oral and oropharyngeal squamous cell carcinoma using ultrasonographyguided cytology: is there a role for identification of the sentinel node? Head Neck 24:282-289

128. van der Haring IS, Schaapveld MS, Roodenburg JL, de Bock GH (2009) Second primary tumours after a squamous cell carcinoma of the oral cavity or oropharynx using the cumulative incidence method. Int J Oral Maxillofac Surg 38:332-338 